\title{
Discussion of the Measurement Invariance Across Gender in the Version of the Part of Responsiveness in Servqual Scale
}

\author{
Dr. Feng-Ming Liu \\ Assistant Professor \\ Lan Yang Institute of Technology, Taiwan \\ nicotainan@gmail.com \\ Dr. Shih-Lung Ching \\ Principle/ Assistant Professor \\ Fusing Junior High School, Taiwan \\ jng387@gmail.com
}

\author{
Dr. Yun-Chin Huang \\ Assistant Professor \\ Taipei City University of Science \& Technology, Taiwan \\ denise.sf@gmail.com \\ Dr. Yu-Jia Hu \\ Assistant Professor \\ Lan Yang Institute of Technology, Taiwan \\ h090805@gmail.com
}

\begin{abstract}
This quantitative research was to examine the measurement invariance across gender for the part of Responsiveness in SERVQUAL Scale for retail chain stores business in Taiwan. The SERVQUAL Scale has become the most common questionnaire for investigating the perception of service quality in current service industry. However, the measurement invariance issue across groups in SERVQUA only received very few considerations. Previous studies also revealed there was the significant relationship between gender and service quality. The participants in this research were selected as customers from four retail chain stores in Taiwan, resulting in 200 individual surveys for analysis. The outcomes indicated the Taiwan version of Responsiveness 5-item scale achieved strict measurement invariance across gender. The property of factor loading, structural covariances and measurement residuals across gender were invariant. Finally, this research generated the recommendations for retail chain stores business in Taiwan and suggested future scholar studies.
\end{abstract}

Keywords-service quality, SERVQUAL, responsiveness, measurement invariance, retail chain stores, Taiwan

\section{RESEARCH BACKGROUND AND LITERATURE REVIEW}

The most prominent questionnaire for measuring service quality - SERVQUAL Scales was created by Parasuraman, Zeithaml, and Berry [1]. The SERVQUAL Scales provided five dimensions to measure the service quality, such as tangible, responsiveness, reliability, empathy, and assurance. Service quality has been described as the critical factor to sustain the proficiency for company development. Even though this questionnaire has applied broadly to perform studies for service quality in industries or countries, only some studies have examined the issues of the measurement invariance for SERVQUAL Scale. In addition, numerous researchers (Baird [2], Blustain [3], Canary and Hause [4]) have suggested theories for gender difference in numerous facets on psychology and manner, such as social talents, communications, work approaches and so on. People also pay much attention on the issue of the increasing woman buying power for those years, and the studies for gender differences in consumer behavior have become important topic for current academy researcher and marketing administrators in business. Research by Meyers-Levy and Maheswarm [5], and Mitchell and Walsh [6] revealed gender difference will lead to different buyer behavior. Mitchell and Walsh [6] also claimed gender differences resulted in different decision making process. These theories and studies suggested that there is the significant relationship between gender and service quality. Therefore, this research expanded previous research and applied SEM approach to evaluate the measurement invariance across gender for the component of Responsiveness in SERVQUAL Scale in retail chain stores business of Taiwan.

\section{RESEARCH PURPOSES AND HYPOTHESES}

Based on the previous studies and theories, the purposes and the significance for this research were: (a) to examine the measurement invariance across gender for the part of Responsiveness in SERVQUAL Scale in retail chain stores business of Taiwan, (b) to have the recommendations for managerial application of retail chain stores business, and (c) to identify areas for future scholarly inquiry. Byrne [7] suggested the tests for multigroup invariance are: (a) factor loadings, (b) factor covariances, and (c) structural regression paths. Following this concept, the researcher proposed three hypotheses as follows. Jöreskog [8] recommended the first step to measure the equality of covariance structure are the test of null hypothesis. The groups were considered to have equivalent covariance structures if $\mathrm{H} 0$ cannot be rejected. Following these concept, the researcher proposed three null hypotheses as follows: Hypothesis 1: The measurement weights for 5 items are invariant across gender., Hypothesis 2: 
The structural co variances for 5 items are invariant across gender., and Hypothesis 3: The measurement residuals for 5 items are invariant across gender.

\section{INSTRUMENTATION}

The Responsiveness of five items in this research were little modified from the SERVQUAL Scales [1]. Following Five Likert Scale: strongly disagree, disagree, neutral, agree, strongly agree, the five items were: (a). Service personnel can correctly answer my question., (b). Service personnel provide me kind service., (c). Service personnel provide various service for different customers. (d). Service personnel is polite, and (e). Service personnel handle the problem in on time manner. Kenny [9] suggested four indicators are better than three indicators, while five indicators are slightly better than four indicators, and more than 5 indicators are useless and unnecessary. Bollen [10], Kline [11], and Mulaik [12] also agreed with this view.

Studies by $\mathrm{Hu}$ [13] [14] [15]have demonstrated the validity and reliability for this scale were reasonable and acceptable. The customers from four retail chain stores in the Kaohsiung city of south Taiwan attended this research. The pretest was conducted with Item Analysis in 50 samples. The researcher applied the method of random sampling. Each store randomly invited volunteer customers who shopping in stores to participate the questionnaire survey. The total number of valid responses was 200 (not including 15 invalid response), providing an adjusted response rate of $93 \%$.

\section{ANALYSIS OF RESULTS}

The research unitized Structure Equating Modeling (SEM) by Analysis of Moment Structure (AMOS) software to test the model structure and hypotheses in this study. The factor analysis for five Responsiveness items was showed as Figure One. For model fit issues: The Chi-Square value was 32.030. The Normedo value was 6.406. Ullman [16] claimed the Normedo value should below 2.00. The Goodness of Fit Index (GFI) value was .941, and scholars recognized the GFI value should greater than .900 . The Adjusted Goodness of Fit Index (AGFI) value was .941. Macallum and Hong [17] suggested AGFI value should greater .800. The Comparative Fit Index (CFI) value was .920, while the CFI value has been discussed its value should close to 1.00. The Root Mean Square Error of Approximation (RMESA) value was .165, while $\mathrm{Hu}$ and Bentler [18] suggest RMESA value should close to .06. Therefore, the overall model fit is reasonable.

The outcomes of multi-sample analysis for the unconstrained and the three constrained models were listed as Table one. The unconstrained model showed an acceptable baseline model for both male and female. The multi-sample analysis also showed the indexes of model fit for three constrained models (measure weights, structural covariances, and measurement residuals) across gender, and these indexes indicated the three constrained models were accepted.

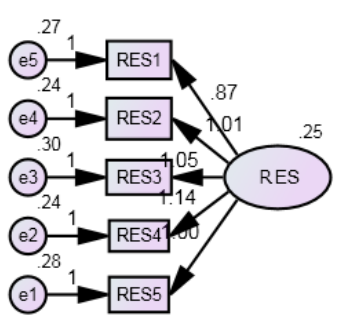

Chi-square $=32.030$ degree of freedom $=5$ normed chi-dquare $=6.406$ GFI=.941 $\mathrm{AGF}|=.824 \mathrm{CF}|=.920$ RMSEA $=.165$

Figure One: Factor Analysis for Responsiveness Items

Table One: Model Fit Indexes for Models

\begin{tabular}{|c|rrrrrrc|}
\hline Model & $\chi^{2}$ & DF & P & $\chi 2 /$ DF & NFI & CFI & RMSEA \\
\hline A & 31.247 & 10 & .001 & 3.125 & .913 & .937 & .104 \\
B & 33.777 & 14 & .002 & 2.413 & .906 & .941 & .084 \\
C & 33.803 & 15 & .004 & 2.254 & .905 & .944 & .080 \\
D & 37.517 & 20 & .010 & 1.876 & .895 & .948 & .067 \\
\hline
\end{tabular}

Note:A: Unconstrained, B: Measurement weights, C:Structural co variances, D: Measurement residuals

Table Two: Nested Model Comparisons

\begin{tabular}{|c|rrr|}
\hline Model & DF & $\chi 2$ & $\mathrm{P}$ \\
\hline Measurement weights & 4 & 2.530 & .639 \\
Structural covariances & 1 & 0.026 & .872 \\
Measurement residuals & 5 & 3.715 & .591 \\
\hline
\end{tabular}

The test results for nested model comparisons were showed in Table Two. The $\chi 2$ difference test $(\chi 2(4)=2.530$, p>.05) between baseline model and constrained model for measurement weights was not significant, and Hypothesis 1 was not rejected. This result indicated the factor loadings across gender in this scale were measurement invariant. In addition, the result of the $\chi 2$ difference test between baseline model and constrained model for structural covariances $(\chi 2(1)=.026, p>. .05)$ was not significant, and Hypothesis 2 was not rejected. This result indicated that, aside from the factor loadings, structural covariances of this scale was measurement invariant across the gender. Finally, the result of $\chi 2$ difference test for measurement residuals $(\chi 2(5)=3.715$, p>.05) was not significant, indicating the residuals across gender in this scale were measurement invariant, too. Therefore, all three null hypotheses are not rejected in this research.

\section{CONCLUSIONS AND RECOMMENDATIONS}

The outcomes indicated this Taiwan version of Responsiveness 5-item scales of SERVQUAL Questionnaire were strict measurement invariance across the gender, including invariance of factor loadings, structural covariances and measurement residuals. The results did not consist with the views of Meyers-Levy and Maheswarm [5], and Mitchell and Walsh [6] suggested gender differences will lead to dissimilar buyer actions. Although this model was fully measurement invariance, Milfont and Fischer [19] claimed full measurement invariance is questionable to hold in reality. 
Based on the research by $\mathrm{Hu}$ [20], the part of Tangibles in SERVQUAL Questionnaire is partial measurement invariance across the gender. Those studies revealed the researcher should keep strict manner to conduct research for multiple items in questionnaire for the issues of measurement invariance across group. And this study suggested the effect of measurement invariance across genders was not significant when apply the part of Responsiveness in SERVQUAL Scale for conducting studies, specially exploring the service quality for the retail chain stores business in Taiwan.

\section{Acknowledgments}

The author would like to thank Dr. Yun-Chin Huang, Dr. Shih-Lung Ching, Dr. Yu-Jia Hu. All the researchers distributed their efforts and spent lots time in discussing the SEM theories and practices during this research.

\section{References}

[1] Parasuraman, A., Zeithaml, V. A., \& Berry, L. L. (1988). Communication and control processes in the delivery of service process. Journal of Marketing, 52(1), 36-58.

[2] Baird, J. E., Jr. (1976). Sex differences in group communication: A review of relevant research. Quarterly Journal of Speech, 62, 179-192.

[3] Blustain, S. (2000). The new gender wars. Psychology Today, 33,

[4] Canary, J. D., \& Hause, S. K. (1993). Is there any reason to research sex differences in communication? Communication Quarterly. 41(2), 129144.

[5] Meyers-Levy, J., \& Maheswaran, D. (1991). "Exploring Differences in Males' and Females' Processing Strategies. Journal of Consumer Research, 18(1), 63-70.

[6] Mitchell, V. W., \& Walsh, G. (2004). Gender differences in German consumer decision making style. Journal of Consumer Behavior, 3(4), 331-346.

[7] Byrne, B. M. (2010). Structural Equation Modeling With AMOS: Basic Concepts, Applications, and Programming, 2 ed, Routledge, Taylor \&
Francis Group, NJ. 197-200.Styles. Journal of Consumer Behavior, 3(4), 331-346.

[8] Jöreskog, K.G. (1971). Simultaneous factor analysis in several populations. Psychometrika, 36, 409-426.

[9] Kenny, D. A. (1979). Correlation and causality. New York: Wiley.

[10] Bollen, K. A. (1989). Structural equations with latent variables. New York: Wiley.

[11] Kline, R. B. (1998). Principles and practice of structural equation modeling. New York: Guilford Press.

[12] Mulaik, S. A. (1994). The critique of pure statistics: Artifact and objectivity in multivariate statistics. In B. Thompson (Ed.), Advances in social science methodology, 3, 247-296. Greenwich, CT: JAI. (397,399)

[13] Hu, Y. J. (2011). How Brand Equity, Marketing Mix Strategy and Service Quality Affect Customer Loyalty: The Case of Retail Chain Stores in Taiwan. International Journal of Organizational Innovation, 4(1), 59-73.

[14] Hu, Y. J. (2012). The moderating effect of brand equity and the mediating effect of marketing mix strategy on the relationship between service quality and customer loyalty: The case of retail chain stores in Taiwan. International Journal of Organizational Innovation, 5(1), 155162.

[15] Hu, Y. J. (2013). Using structural equation modeling to evaluate a consumer behavior model: the case of retail chain stores in Taiwan. International Journal of Organizational Innovation, 6(1), 121-127.

[16] Ulman, J. B. (2001). Structure equation modeling. In Tabachnick, B. G., and Fidell, L. S. (2001). Using Multivariate Statistics (4 ${ }^{\text {th }}$ ed.): 653-771. Needham Heights, MA: Allyn and Bacon.

[17] Macallum, R. C. \& Hong, S. (1997). Power analysis in covariance structure modeling using GFI and AGFI. Multivariate Behavioral Research, 32, 193-210.

[18] Hu, L., \& Benter, P. M. (1999). Cutoff criteria for fit indexes in covariance structure analysis: Conventional criteria versus new alternatives. Structural Equation Modeling, 6(1), 1-55.

[19] Milfont, T. L., \& Fischer, R. (2010). Testing measurement invariance across groups: Applications in cross-cultural research. International Journal of Psychological, 3(1), 110-121.

[20] Hu, Y. J. (2014). Assessing Measurement Invariance Across Gender In The Version Of The Part Of Tangibles In Servqual Scale For Retail Chain Stores Business In Taiwan. International Journal of Organizational Innovation, 7(1), 181-187. 